\title{
TEKNIK PENGELOLAAN USAHATANI TANAMAN CABAI BERKELANJUTAN DI DATARAN TINGGI KECAMATAN CIKAJANG KABUPATEN GARUT (Management Technique of Sustainable Red Pepper Crop Farming System in Upland Distric of Cikajang Garut Regency)
}

\author{
Wa Ode Muliastuty ${ }^{1,2^{*}}$, Santun R.P. Sitorus ${ }^{3}$, Roedhy Poerwanto ${ }^{4}$ \\ dan Hartrisari Hardjomidjojo ${ }^{5}$ \\ ${ }^{1}$ Program Studi Pengelolaan Sumberdaya Alam dan Lingkungan, Institut Pertanian Bogor, \\ Jl. Raya Darmaga Bogor, 16680. \\ ${ }^{2}$ Program Studi Agroteknologi, Fakultas Pertanian, Universitas Halu Oleo, \\ Kampus Hijau Bumi Tridharma, Jl. H.E.A. Mokodompit, Kendari, 93232. \\ ${ }^{3}$ Departemen Ilmu Tanah dan Sumberdaya Lahan, Fakultas Pertanian, Institut Pertanian Bogor, \\ Jl. Raya Darmaga Bogor, 16680. \\ ${ }^{4}$ Departemen Agronomi dan Hortikultura, Fakultas Pertanian, Institut Pertanian Bogor, \\ Jl. Raya Darmaga Bogor, 16680. \\ ${ }^{5}$ Departemen Teknologi Industri Pertanian, Fakultas Teknologi Pertanian, Institut Pertanian Bogor, \\ Jl. Raya Darmaga Bogor, 16680. \\ *Penulis korespondensi. Tel: 08164312346. Email: mafaz_unhalu@yahoo.com.
}

Disetujui: 28 Oktober 2015

\begin{abstract}
Abstrak
Permasalahan yang dihadapi dalam usahatani cabai merah dataran tinggi adalah penurunan produktivitas tanaman akibat ketidaksesuaian agroteknologi dengan karakteristik lahan dan kebutuhan tanaman. Hal ini mempercepat proses erosi dan meningkatkan kehilangan lapisan atas tanah yang lebih subur sehingga menurunkan produktivitas lahan. Penelitian ini bertujuan untuk mengetahui besar erosi, menganalisis kontribusi pendapatan usahatani terhadap Kebutuhan Hidup Layak (KHL) petani, dan mengkaji alternatif teknik Konservasi Tanah dan Air (KTA). Erosi dianalisis menggunakan persamaan USLE. Pendapatan usahatani menggunakan analisis anggaran arus uang tunai. KHL petani dihitung berdasarkan jumlah anggota keluarga petani, didekati dari kebutuhan fisik minimal ditambah kebutuhan hidup tambahan. Teknik konservasi tanah diuji pada percobaan petak erosi berukuran 2 x 20 meter dan dibuat pada kemiringan lereng 40 \%. Rancangan percobaan menggunakan rancangan acak kelompok dua faktor. Pertama adalah pola tanam, yaitu cabai merah monokultur $\left(\mathrm{T}_{1}\right)$ dan cabai merah tumpangsari dengan kubis $\left(\mathrm{T}_{2}\right)$. Kedua adalah teknik konservasi tanah, yaitu guludan searah lereng sebagai kontrol $\left(\mathrm{K}_{1}\right)$, guludan searah lereng + guludan memotong lereng jarak 6,60 meter $\left(\mathrm{K}_{2}\right)$, guludan memotong lereng $\left(\mathrm{K}_{3}\right)$, dan guludan memotong lereng miring $20^{\circ}\left(\mathrm{K}_{4}\right)$. Hasil penelitian menunjukkan bahwa semakin curam kemiringan lereng maka erosi semakin besar melebihi batas ETol dan kontribusi pendapatan usahatani terhadap KHL petani semakin rendah. Pola tanam cabai merah monokultur mempunyai erosi yang lebih besar dan kontribusi pendapatan terhadap KHL lebih kecil daripada tumpangsari. Teknik konservasi $T_{1} K_{3}, T_{2} K_{3}, T_{1} K_{4}$ dan $T_{2} K_{4}$ dapat diterapkan pada lahan dataran tinggi karena mampu menurunkan erosi $\leq$ ETol $\left(30,92\right.$ ton.ha $^{-1} \cdot$ th $\left.^{-1}\right)$ dan meningkatkan pendapatan usahatani $\geq$ KHL (Rp. $23.920 .000 \mathrm{kk}^{-1} . \mathrm{th}^{-1}$ ), sehingga keberlanjutan lingkungan dan ekonomi dapat tercapai.
\end{abstract}

Kata kunci: cabai merah, erosi, konservasi tanah dan air, usahatani.

\begin{abstract}
The problems encountered in red pepper farming on the upland area is the decrease in the crops productivity due to a mismatch between agrotechnology with the land characteristics and the needs of the crops. This condition accelerates the erosion process and increase the loss of top soil, which are more fertile. All of those things has in turn decrease land productivity. This objectives of the study are to gain knowledge about the extension of erosion, to analyze the contribution of farm income to the farmers Need of Decent Living (NDL), and to study alternative technique of soil and water conservation. Erosion is analyzed by USLE equations. Farm income is analyzed by using cash flow budget analysis. NDL is calculated based on amount of family member in one family farmer, which is approached by minimum physical necessities added by additional life necessities. Soil conservation technique were tested in erosion experimental plots with 2 x 20 meters size made at the $40 \%$ slope. Randomized block design is used that are consist of two factors. The first is cropping pattern which are monoculture red pepper $\left(T_{1}\right)$ and intercropping red pepper with cabbage $\left(T_{2}\right)$. The second is soil conservation technique which are the ridges in the direction of the slope as the control $\left(K_{1}\right)$, the ridges in the direction of the slope + the ridges cut off the slopes in every 6.6 meters $\left(K_{2}\right)$, the ridges across the slope $\left(K_{3}\right)$, and ridges
\end{abstract}


across the slope with $20^{\circ}$ tilted $\left(K_{4}\right)$. The research result shows that as the slope is getting steeper, the erosion is getting higher and exceeded the TSL and the contribution of farm income to the farmers NDL is getting lower. Monoculture red pepper cropping patterns have a greater erosion and the contribution of farm income to the farmers NDL is smaller than the intercropping. Conservation technique $T_{1} K_{3}, T_{2} K_{3}, T_{1} K_{4}$ and $T_{2} K_{4}$ can be applied to the upland area because it is capable to decrease the erosion less than or equal to the TSL (30.92 ton.ha ${ }^{-1} . \mathrm{yr}^{-1}$ ) and increasing farming income more than or equal to the farmers NDL (Rp. 23,920,000 household $\left.{ }^{-1} \cdot \mathrm{yr}^{-1}\right)$, and therefore the sustainability of the environment and the economy can be accomplished.

Keywords: erosion, red pepper, soil and water conservation, sustainable farming system.

\section{PENDAHULUAN}

Keterbatasan lahan pertanian khususnya untuk komoditas-komoditas hortikultura menyebabkan lahan dataran tinggi menjadi pilihan penggunaan lahan untuk pertanian (Agus dkk., 2006; Pasandaran, 2006). Pemanfaatan lahan pertanian di dataran tinggi memiliki kompleksitas pengelolaan yang lebih tinggi dan produktivitas yang lebih rendah dibandingkan dengan lahan pertanian di dataran rendah (Prasetyo dan Suriadikarta, 2006; Dariah, 2007).

Berdasarkan sifat-sifat bawaan lahan dataran tinggi seperti kemiringan lereng dan kepekaan tanah terhadap erosi serta curah hujan yang tinggi, maka peluang terjadinya erosi, terutama pada lahan yang digunakan untuk pertanaman sayuran tergolong tinggi (Hogarth dkk., 2004; Gangcai, 2005; Dariah, 2007). Praktek pengelolaan lahan yang diterapkan petani saat ini menyebabkan multifungsi (eksternalitas positif) usahatani sayuran, khususnya dalam pengendalian erosi dan banjir tidak optimal. Masalah degradasi lahan usaha dan leveling-off produksi sayuran umumnya terkait dengan fragmentasi lahan usaha, yaitu lahan usahatani keluarga yang sempit sehingga terjadi inefisiensi pengelolaan usahatani (Adiyoga dkk., 2000; Soetiarso dan Setiawati, 2010) dan sistem pengelolaan tanah yang tidak berwawasan konservasi fisik maupun kesuburan (Sinukaban, 2007; El Kateb dkk., 2013; Lihawa dkk., 2014).

Berbagai hasil penelitian erosi di lahan usahatani sayuran dataran tinggi dengan kemiringan lereng di atas $15 \%$ menunjukkan bahwa besaran erosi yang terjadi berkisar antara $87-652$ ton.ha ${ }^{-1}$.th ${ }^{1}$ (Arsanti dan Boehme, 2006; Firmansyah, 2007; Zhou, 2008; Sutrisna dkk., 2010). Bila mengacu pada batas erosi yang ditoleransi sekitar 13,5 ton.ha ${ }^{-}$ ${ }^{1}$. th $^{-1}$ (Thomson, 1957 dalam Arsyad, 2010), maka tingkat erosi yang terjadi pada lahan sayuran ini tergolong membahayakan (Shukle dan Lal, 2005; Sutono, 2008).

Data kuantitatif dan karakteristik spasial penggunaan lahan dataran tinggi tersebut menunjukkan bahwa kesesuaian lahan untuk penggunaan lahan dataran tinggi sebagai lahan pertanian tanaman semusim menunjuKkan kecenderungan rendah ataupun tidak sesuai. Nilai harapan yang rendah tersebut dapat ditingkatkan menjadi berkelanjutan dengan peningkatan upaya dari sisi teknis, tenaga dan biaya oleh petani. Hipotesisnya adalah output pertanian di dataran tinggi akan mendekati output pertanian di dataran rendah, namun menjadi tidak efisien karena biaya, waktu dan tenaga kerja yang lebih banyak. Oleh karena itu, pemilihan komoditas unggulan yang memiliki nilai ekonomi tinggi dapat menjadi pilihan bagi keberlanjutan pertanian di lahan dataran tinggi.

Cabai merah merupakan komoditas sayuran yang saat ini menjadi primadona petani, termasuk pada penggunaan lahan dataran tinggi di Jawa Barat. Cabai merah menjadi komoditas sayuran penting, mempunyai nilai ekonomis yang tinggi seiring dengan peningkatan jumlah penduduk dan berkembangnya industri yang membutuhkan bahan baku cabai. Konsumsi cabai merah cenderung mengalami peningkatan dari tahun ke tahun. Pada tahun 2013, konsumsi cabai merah sebesar 1,66 kg.kapita ${ }^{-1} \cdot \mathrm{th}^{-1}$ dan pada tahun 2014 mengalami peningkatan sebesar 1,68 kg.kapita ${ }^{-1} \cdot \mathrm{th}^{-1}$ atau naik $1,20 \%$ dibandingkan tahun sebelumnya (Respati dkk., 2014) . Selain untuk konsumsi rumah tangga, kebutuhan cabai merah untuk industri makanan dan kebutuhan ekspor juga terus meningkat, sementara itu produksi cabai merah dalam negeri mengalami penurunan.

Secara nasional data statistik menunjukkan bahwa penambahan luas pertanaman cabai merah tidak linear dengan produktivitasnya. Tahun 2012 luas areal pertanaman cabai merah tercatat sebesar 242.366 ha, dengan rata-rata produktivitas 6,84 ton.ha ${ }^{-1}$, dan tahun 2013 luas areal pertanaman cabai merah meningkat menjadi 249.232 ha namun produktivitasnya menurun menjadi 6,63 ton.ha ${ }^{-1}$ (Anonim, 2014). Angka tersebut relatif rendah dibandingkan dengan potensi produktivitas cabai secara nasional yang mencapai $12-15$ ton.ha $^{-1}$ (Soetiarso dan Setiawati, 2010). Faktor penyebab produksi cabai merah yang rendah tersebut antara lain produktivitas lahan yang rendah akibat erosi (Sumarni dkk., 2006), penguasaan teknologi budidaya cabai yang rendah (Berke dkk., 2005), serangan organisme pengganggu tanaman (Gunaeni dan Wulandari, 2010), dan belum banyak digunakan 
varietas berdaya hasil tinggi (hibrida) dan berkualitas (Daryanto dkk., 2010).

Peningkatan permintaan komoditas cabai merah dihadapkan dengan permasalahan ketersediaan lahan, baik dari sisi luas lahan maupun dari sisi karakteristik lahannya tidak mendukung untuk peningkatan produktivitas tanaman cabai merah. Peningkatan produktivitas cabai merah selain dengan penggunaan varietas unggul dan pengendalian hama penyakit, perlu didukung teknik budidaya dan teknik Konservasi Tanah dan Air (KTA) yang tepat untuk mencapai hasil yang optimal (Sumarni dkk., 2006; Sinukaban, 2007; Suwandi, 2009). Oleh karena itu, perlu adanya pengelolaan usahatani tanaman cabai merah di lahan dataran tinggi secara berkelanjutan dalam upaya peningkatan produksi dan pendapatan petani, sekaligus mengurangi erosi tanah melalui pemilihan dan penerapan teknologi konservasi spesifik lokasi, sesuai dengan kondisi lingkungan setempat meliputi kondisi biofisik lahan (tanah, iklim, air) dan sosial ekonomi.

Tujuan penelitian ini adalah untuk mengetahui besar erosi yang terjadi pada lahan usahatani tanaman cabai merah, menganalisis kontribusi pendapatan usahatani cabai merah dataran tinggi terhadap Kebutuhan Hidup Layak (KHL) petani, dan mengkaji alternatif teknik KTA yang dapat mengendalikan erosi dan meningkatkan produksi tanaman cabai merah.

\section{METODE PENELITIAN}

\section{Waktu dan Lokasi}

Waktu penelitian berlangsung selama 12 bulan, mulai bulan Januari 2013 sampai Desember 2013.

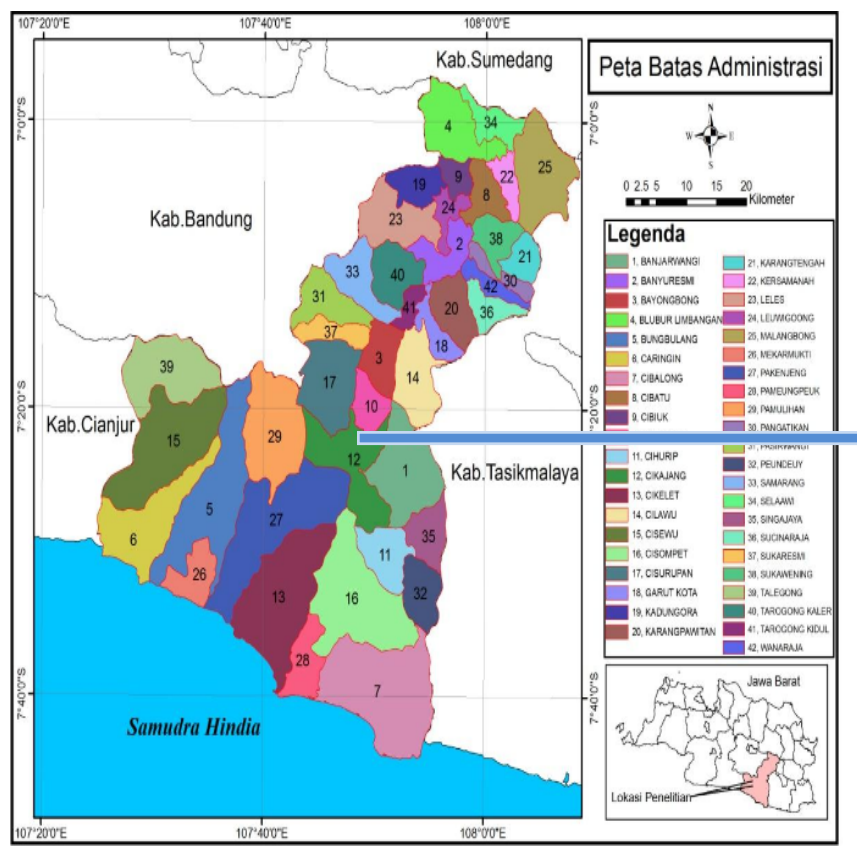

Gambar 1. Lokasi penelitian.
Penelitian dilaksanakan di Kecamatan Cikajang Kabupaten Garut (Gambar 1). Analisis contoh tanah dilakukan di Laboratorium Tanah, Fakultas Pertanian, Institut Pertanian Bogor (IPB).

\section{Bahan dan Alat}

Bahan yang digunakan adalah peta administrasi wilayah Kabupaten Garut, peta kemiringan lereng, peta penggunaan lahan, dan peta tanah (skala $1: 50$ 000), bibit cabai merah dan kubis, pupuk, pestisida, ajir, tali, drum, terpal, ember, pipa paralon, bahan untuk analisis sifat kimia tanah di laboratorium dan kuesioner untuk wawancara sosial ekonomi.

Peralatan yang digunakan yaitu meteran, infiltrometer, ombrometer, kamera digital, cangkul, dan pisau, peralatan yang digunakan di laboratorium, seperangkat personal komputer. Software yang digunakan untuk analisis data adalah MS Excel dan Minitab.

\section{Prosedur Penelitian \\ Teknik pengumpulan data}

Penentuan lokasi dilakukan secara sengaja (purposive) berdasarkan data base Dinas Tanaman Pangan dan Hortikultura Kabupaten Garut, bahwa Kecamatan Cikajang merupakan sentra produksi cabai merah terbesar di Kabupaten Garut (Anonim, 2013). Jumlah petani cabai merah di Kecamatan Cikajang (N) adalah 218 petani. Petani responden dipilih secara acak menggunakan rumus Slovin (Sevila dkk., 1993) sehingga jumlah responden (n) adalah 69 petani. Petani responden di stratified berdasarkan kemiringan lereng dan pola tanam (Tabel 1).

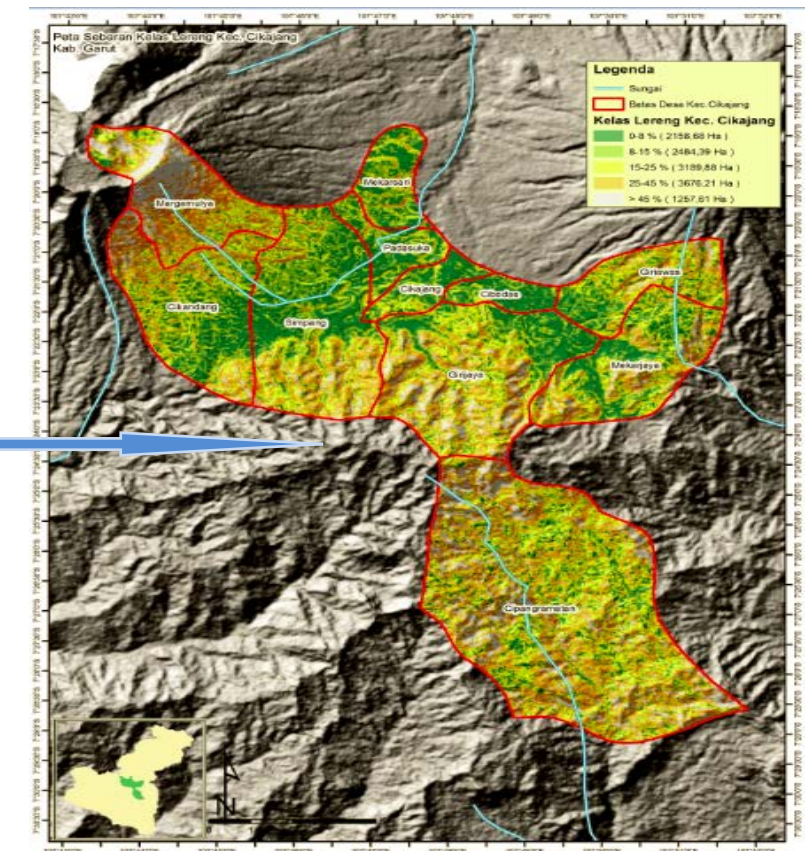


Tabel 1. Jumlah petani responden berdasarkan kemiringan lereng dan pola tanam.

\begin{tabular}{lcc}
\hline \multicolumn{1}{c}{ Uraian } & $\begin{array}{c}\text { Jumlah } \\
\text { (orang) }\end{array}$ & Persentase (\%) \\
\hline Kemiringan Lereng & & \\
$\bullet 10 \%$ & 29 & 42,0 \\
$\bullet 20 \%$ & 28 & 40,6 \\
• $40 \%$ & 12 & 17,4 \\
\hline Jumlah & 69 & 100,0 \\
\hline Pola tanam & & \\
• Monokultur & 41 & 59,4 \\
• Tumpangsari & 28 & 40,6 \\
\hline Jumlah & 69 & 100,0 \\
\hline
\end{tabular}

Sumber : Data primer (2014).

Pengumpulan data biofisik (curah hujan, sifatsifat tanah, dan karakteristik lahan) dilakukan dengan metode survei dan analisis di laboratorium. Pengumpulan data sosial ekonomi (karakteristik petani, input usahatani, produksi tanaman, teknik budidaya) dilakukan melalui survei lapangan dan wawancara dengan petani responden. Pengumpulan data aliran permukaan, erosi, kehilangan hara dan produksi tanaman melalui percobaan petak erosi ukuran 2 x 20 meter (panjang petak searah lereng) dan dibuat pada kemiringan lereng $40 \%$.

\section{Rancangan percobaan konservasi tanah dan air}

Penelitian dirancang secara faktorial dalam Rancangan Acak Kelompok (RAK) dengan dua faktor. Faktor pertama adalah pola tanam, yaitu cabai merah monokultur $\left(\mathrm{T}_{1}\right)$ dan cabai merah tumpangsari dengan kubis $\left(\mathrm{T}_{2}\right)$. Faktor kedua adalah teknik KTA, yaitu guludan searah lereng sebagai kontrol $\left(\mathrm{K}_{1}\right)$, guludan searah lereng + pembuatan guludan memotong lereng setiap jarak 6,60 $\mathrm{m}\left(\mathrm{K}_{2}\right)$, guludan memotong lereng $\left(\mathrm{K}_{3}\right)$, dan guludan memotong lereng miring $20^{\circ}\left(\mathrm{K}_{4}\right)$. Setiap percobaan diulang sebanyak 3 kali sehingga diperoleh 24 petak percobaan.

Pengukuran aliran permukaan dan erosi dengan Metode Multi-slot Diviser. Pembatas petakan percobaan menggunakan plastik terpal yang dibenamkan $\pm 30 \mathrm{~cm}$ ke dalam tanah dan $\pm 40 \mathrm{~cm}$ di atas permukaan tanah. Bak penampung aliran permukaan dan erosi berukuran 2 × 0,5 x 0,5 m dengan lubang diameter $5 \mathrm{~cm}$ pada $5 \mathrm{~cm}$ dari bibir bak dan satu lubang yang ditengah dihubungkan dengan pipa paralon diameter $5 \mathrm{~cm}$ untuk mengalirkan luapan ke bak kecil 0,5 x 0,5 x 0,5 m. Setelah tanah diolah sempurna dibuat bedengan dengan ukuran lebar $80 \mathrm{~cm}$, tinggi bedengan $40 \mathrm{~cm}$, panjang guludan $20 \mathrm{~m}$, dan jarak antar bedengan 40 $\mathrm{cm}$. Penanaman cabai menggunakan jarak tanam 60 x $50 \mathrm{~cm}$. Bibit yang digunakan adalah varietas $\mathrm{Hot}$ Beauty. Penanaman bibit kubis (Varietas Master Grand) diantara tanaman utama (tanaman cabai merah) mengikuti jarak tanam tanaman cabai merah.
Pupuk dasar yang digunakan terdiri dari pupuk kandang (40 ton.ha ${ }^{-1}$ ) dan pupuk NPK 15:15:15 (500 kg.ha $\left.{ }^{-1}\right)$. Aplikasi pupuk dasar dilakukan 1 Minggu Sebelum Tanam (MST). Pupuk susulan untuk tanaman cabai merah digunakan pupuk NPK 15:15:15 (500 kg.ha ${ }^{-1}$ ). Aplikasi pupuk susulan dilakukan dengan cara dicairkan dan disiramkan (dicor) di sekitar tanaman cabai mulai umur 14 Hari Setelah Tanam (HST) dengan interval 10 hari sekali. Pada perlakuan tumpangsari cabai merah + kubis, penggunaan NPK ditambah 120 kg.ha ${ }^{-1}$ untuk pupuk susulan kubis dengan aplikasi dicor di sekitar tanaman kubis mulai umur 14 HST dan interval 10 hari sekali.

Curah hujan diukur dengan menggunakan ombrometer yang dipasang di lokasi penelitian. Volume aliran permukaan/petak/kejadian hujan diukur dengan cara mengukur tinggi muka air dalam bak penampung. Jumlah tanah tererosi/petak/kejadian hujan ditentukan melalui analisis sampel air aliran permukaan yang tertampung dalam drum dan sampel sedimen dalam bak penampung. Kandungan unsur hara pada sedimen, antara lain $\mathrm{N}$ total diukur dengan metode Kjeldahl, $\mathrm{P}$ dengan metode Bray, $\mathrm{K}$ dengan ekstraksi ammonium asetat, dan bahan organik dengan metode Walkey dan Black. Data produksi diukur pada saat panen.

\section{Analisis Data}

Prediksi erosi dihitung menggunakan rumus Universal Soil Loss Equation (USLE) (Wischmeier dan Smith, 1978 dalam Arsyad, 2010) dan ETol menggunakan konsep kedalaman ekivalen dan umur guna tanah (Hammer, 1981 dalam Arsyad, 2010). Pendapatan usahatani dihitung berdasarkan analisis finansial dengan analisis anggaran arus uang tunai (Soekartawi, 2006). Kebutuhan Hidup Layak (KHL) dihitung berdasarkan rata-rata jumlah anggota satu keluarga petani, didekati dari Kebutuhan Fisik Minimal (KFM) ditambah dengan Kebutuhan Hidup Tambahan (KHT) (Sinukaban, 2007). Pengaruh teknik KTA terhadap aliran permukaan, erosi, kehilangan unsur hara, dan produksi tanaman dianalisis menggunakan analisis sidik ragam pada taraf $5 \%$. Apabila hasilnya berbeda nyata, dilakukan uji berpasangan nilai tengah Beda Nyata Terkecil (BNT).

Rekomendasi alternatif pengelolaan usahatani tanaman cabai merah dataran tinggi berkelanjutan disusun berdasarkan kondisi biofisik dan kondisi sosial ekonomi, serta alternatif teknik KTA. Nilai prediksi erosi dan pendapatan usahatani digunakan sebagai indikator keberlanjutan usahatani (prediksi erosi $\leq$ nilai ETol dan pendapatan usahatani $\geq$ nilai KHL). 


\section{HASIL DAN PEMBAHASAN}

\section{Prediksi Erosi yang Terjadi Pada Lahan Usahatani Cabai Merah}

Hasil perhitungan prediksi erosi dengan menggunakan metode USLE dapat dilihat pada Tabel 2. Jumlah erosi yang terjadi di lahan usahatani tanaman cabai merah termasuk dalam kategori sangat tinggi dengan nilai Indeks Bahaya Erosi (IBE) lebih dari 10 (IBE > 10). Erosi yang sangat tinggi tersebut disebabkan oleh intensitas hujan yang tinggi dimana intensitas hujan rata-rata di daerah penelitian adalah 158,26 mm.jam ${ }^{-1}$. Menurut Printz (1999) dalam Hardiyatmo (2006) untuk intensitas hujan sekitar $30-60$ mm.jam ${ }^{-1}$ hanya sekitar 10\% dari hujan yang menimbulkan erosi, tetapi untuk intensitas hujan yang lebih besar dari $100 \mathrm{~mm}$. jam $^{-1}$ kemungkinan besar akan menimbulkan erosi. Sifat hujan yang sangat penting mempengaruhi erosi adalah energi kinetik hujan, karena merupakan penyebab utama penghancuran agregat-agregat tanah (Asdak, 2007; Li dkk., 2009; Arsyad, 2010). Goro (2008) dalam penelitiannya menjelaskan bahwa intensitas hujan 60 mm.jam ${ }^{-1}$ menghasilkan energi kinetik 27,45 Joule. $\mathrm{m}^{-2} \cdot \mathrm{mm}^{-1}$ dan setiap penambahan intensitas $10 \mathrm{~mm}$.jam ${ }^{-1}$ bertambah pula energi kinetiknya.

Erosi yang sangat tinggi juga dipengaruhi oleh kemiringan lereng yang curam. Tabel 2 menunjukkan bahwa kenaikan lereng sebesar dua kali lebih curam, maka erosi menjadi 1,3 kali lebih banyak. Dengan demikian semakin curam kemiringan lereng maka semakin besar erosi yang terjadi, jauh melebihi batas ETol. Kondisi kemiringan lereng yang curam tanpa tindakan KTA akan memperbesar jumlah dan kecepatan aliran permukaan, sehingga akan memperbesar energi angkut air. Selain itu semakin miring lereng, maka jumlah butir-butir tanah yang terpercik ke bawah oleh tumbukan butir hujan semakin banyak (Hogarth dkk., 2004; Armand dkk., 2009; Arsyad, 2010).

Efektivitas penutupan tanah dan pengelolaan tanaman yang rendah juga menjadi penyebab erosi. Berdasarkan Tabel 2, pola tanam monokultur memberikan nilai erosi lebih besar dibandingkan dengan pola tanam tumpangsari dengan nilai erosi aktual jauh di atas ETol. Perbedaan erosi antar pola tanam tersebut disebabkan oleh perbedaan nilai $\mathrm{C}$ masing-masing pola tanam, di mana nilai faktor $\mathrm{C}$ tanaman cabai monokultur adalah 0,9 dan nilai faktor C tumpangsari tanaman sayuran adalah 0,495. Menurut Asdak (2007) faktor C menunjukkan keseluruhan pengaruh vegetasi, serasah, kondisi permukaan tanah dan pengelolaan tanaman terhadap besarnya erosi. Semakin besar nilai Faktor C maka semakin besar pula erosi yang terjadi (Zhang dkk., 2004).

Tabel 2. Prediksi erosi, ETol dan IBE berdasarkan pola tanam dan kemiringan lereng di Kecamatan Cikajang.

\begin{tabular}{|c|c|c|c|c|c|c|}
\hline \multirow[t]{2}{*}{ Pola tanam } & & & \multicolumn{3}{|c|}{ Kemiringan lereng (\%) } & \multirow[t]{2}{*}{ Rata - rata } \\
\hline & & & 10 & 20 & 40 & \\
\hline \multirow[t]{3}{*}{ Tumpangsari } & $\mathrm{A}$ & $\left(\right.$ ton.ha $^{-1} \cdot$ th $\left.^{-1}\right)$ & 82,84 & 101,55 & 154,08 & 112,82 \\
\hline & ETol & $\left(\right.$ ton.ha-1 $\cdot$ th $\left.^{-1}\right)$ & 32,22 & 28,47 & 27,60 & 29,43 \\
\hline & IBE & & 12,63 & 20,08 & 26,64 & $19,78 *$ \\
\hline \multirow[t]{3}{*}{ Monokultur } & A & $\left(\right.$ ton.ha-1. th $^{-1}$ ) & 143,38 & 179,72 & 223,10 & 182,07 \\
\hline & ETol & $\left(\right.$ ton.ha-1 $\cdot$ th $\left.^{-1}\right)$ & 34,16 & 31,56 & 31,50 & 32,41 \\
\hline & IBE & & 13,90 & 22,90 & 39,41 & $25,40 *$ \\
\hline \multirow[t]{3}{*}{ Rata-rata } & A & $\left(\right.$ ton.ha ${ }^{-1} \cdot$ th $\left.^{-1}\right)$ & 113,11 & 140,64 & 188,59 & \\
\hline & ETol & (ton.ha-1 $\cdot \mathrm{th}^{-1}$ ) & 33,19 & 30,02 & 29,55 & \\
\hline & IBE & & $13,27 *$ & $21,49 *$ & $33,03 *$ & \\
\hline
\end{tabular}

Sumber : Data primer (2014).

Ket : * Sangat tinggi, A = Erosi, ETol = Erosi yang ditoleransi, IBE = Indeks Bahaya Erosi.

Tabel 3. Luas lahan garapan petani saat ini, pendapatan usahatani dan kontribusi pendapatan usahatani cabai merah terhadap pemenuhan KHL petani berdasarkan pola tanam dan kemiringan lereng.

\begin{tabular}{|c|c|c|c|c|c|}
\hline \multirow[t]{2}{*}{ Pola tanam } & & \multicolumn{3}{|c|}{ Kemiringan lereng (\%) } & \multirow[t]{2}{*}{ Rata-rata } \\
\hline & & 10 & 20 & 40 & \\
\hline \multirow{3}{*}{ Monokultur } & Luas lahan (ha) & 0,35 & 0,25 & 0,20 & 0,27 \\
\hline & Pendapatan (Rp.kk $\left.{ }^{-1} \cdot \mathrm{th}^{-1}\right)$ & 20.676.677 & 10.712 .245 & 5.981 .926 & 12.456 .949 \\
\hline & Kontribusi (\%) & 30,25 & 11,20 & 5,00 & 15,48 \\
\hline \multirow{3}{*}{ Tumpangsari } & Luas lahan (ha) & 0,37 & 0,28 & 0,22 & 0,29 \\
\hline & Pendapatan (Rp.kk $\left.{ }^{-1} \cdot \mathrm{th}^{-1}\right)$ & 22.380 .742 & 12.557.416 & 7.111.936 & 14.016 .698 \\
\hline & Kontribusi (\%) & 34,62 & 14,70 & 6,54 & 18,62 \\
\hline \multirow{3}{*}{ Rata-rata } & Luas lahan (ha) & 0,36 & 0,27 & 0,21 & \\
\hline & Pendapatan (Rp.kk $\left.{ }^{-1} \cdot \mathrm{th}^{-1}\right)$ & 21.528 .710 & 11.634 .831 & 6.546 .931 & \\
\hline & Kontribusi (\%) & 32,44 & 12,95 & 5,77 & \\
\hline
\end{tabular}

Sumber : Data primer (2014). 


\section{Kontribusi Pendapatan Usahatani Cabai Merah Terhadap Kebutuhan Hidup Layak Petani}

KHL petani ditentukan oleh harga beras ratarata per kilogram dan jumlah anggota rumah tangga per kepala keluarga. Dengan harga beras rata-rata adalah Rp. $6.500 \mathrm{~kg}^{-1}$ dan jumlah anggota rumah tangga petani responden rata-rata 4,6 org. $\mathrm{kk}^{-1}$, maka KHL petani cabai merah di Kecamatan Cikajang rata-rata sebesar Rp. 23.920.000 kk $\mathrm{kk}^{-1} \cdot \mathrm{th}^{-1}$ Jumlah pendapatan usahatani cabai merah berdasarkan kemiringan lereng dan pola tanam, serta luas penguasaan lahan saat ini dapat digunakan untuk menghitung kontribusi pendapatan usahatani cabai merah terhadap KHL petani (Tabel 3).

Tabel 3 menunjukkan semakin curam kemiringan lereng, maka kontribusi pendapatan usahatani cabai merah terhadap pemenuhan KHL petani semakin rendah. Hal ini disebabkan luas lahan garapan petani yang semakin sempit dan pendapatan usahatani yang semakin berkurang seiring dengan kemiringan lereng yang semakin curam. Menurut Adiyoga dkk. (2000) luas usahatani sayuran dataran tinggi di tingkat petani umumnya rata-rata hanya 0,2 - 0,3 ha. Selain disebabkan oleh kepemilikan atau lahan garapan yang sempit, kontribusi pendapatan usahatani yang kecil juga karena biaya usahatani sayuran relatif mahal, sehingga berpengaruh terhadap pendapatan petani.

Berdasarkan pola tanam, kontribusi pola tanam tumpangsari lebih tinggi daripada kontribusi pola tanam monokultur. Hal ini disebabkan pendapatan usahatani lebih tinggi karena ada tambahan hasil produksi dari tanaman tumpangsari (kubis). Kontribusi usahatani cabai merah terhadap pemenuhan KHL baik pada pola tanam tumpangsari maupun monokultur masih lebih rendah dari yang dilaporkan Badan Litbang Pertanian (Anonim, 2005), bahwa sumbangan pendapatan usahatani tanaman sayuran terhadap pendapatan rumah tangga petani mencapai $25-35 \%$.

\section{Keberlanjutan Usahatani Cabai Merah Dataran Tinggi}

Indikator keberlanjutan usahatani cabai merah dataran tinggi di Kecamatan Cikajang ditentukan berdasarkan nilai prediksi erosi dan pendapatan usahatani. Suatu usahatani dikatakan berlanjut apabila erosi yang terjadi pada suatu lahan usahatani lebih kecil atau sama dengan nilai ETol dan pendapatan usahatani lebih besar atau sama dengan nilai KHL petani (Sinukaban, 2007). Berdasarkan hasil prediksi erosi, hasil analisis usahatani dan hasil analisis KHL petani dibuat suatu hubungan yang menjelaskan keberlanjutan usahatani cabai merah dataran tinggi (Gambar 2).
Gambar 2 menunjukkan bahwa pendapatan usahatani pada pertanaman cabai merah monokultur dan tumpangsari di tiga kelas kemiringan lereng lebih kecil dari nilai KHL. Hal ini mengindikasikan usahatani cabai merah dataran tinggi di Kecamatan Cikajang belum menunjukkan indikator keberlanjutan ekonomi. Hasil prediksi erosi menunjukkan bahwa besar erosi di lahan usahatani jauh melebihi batas ETol, sehingga usahatani cabai merah daratan tinggi di Kecamatan Cikajang belum menunjukkan indikator keberlanjutan lingkungan. Oleh karena, itu diperlukan penyempurnaan teknik pengelolaan usahatani berupa teknik KTA yang sesuai dan memadai agar sistem usahatani dapat berkelanjutan.

\section{Penentuan Alternatif Teknik KTA}

Untuk menjaga agar kerusakan tanah tidak terjadi dan tanah dapat digunakan secara berkelanjutan, maka nilai erosi harus ditekan menjadi sama atau lebih kecil dari nilai ETol, dengan mencari dan menerapkan tanaman/pola tanam (C) dan tindakan konservasi tanah (P) yang sesuai. Caranya adalah dengan membandingkan nilai ETol dengan erosi yang terjadi pada lahan tersebut tanpa tindakan konservasi, disebut erosi potensial. Jika erosi potensial rata-rata sebesar 626 ton.ha ${ }^{-1} \cdot$ th $^{-1}$ dan nilai ETol rata-rata sebesar 30,92 ton.ha ${ }^{-1} \cdot \mathrm{th}^{-1}$, maka nilai CP rata-rata yang digunakan untuk menekan erosi menjadi sama atau lebih kecil dari ETol adalah 0,05. Dengan demikian alternatif tindakan konservasi yang direkomendasikan adalah guludan tanaman memotong lereng (nilai $\mathrm{CP}=0,03-0,28$ ) (Asmaranto dan Juwono, 2007).

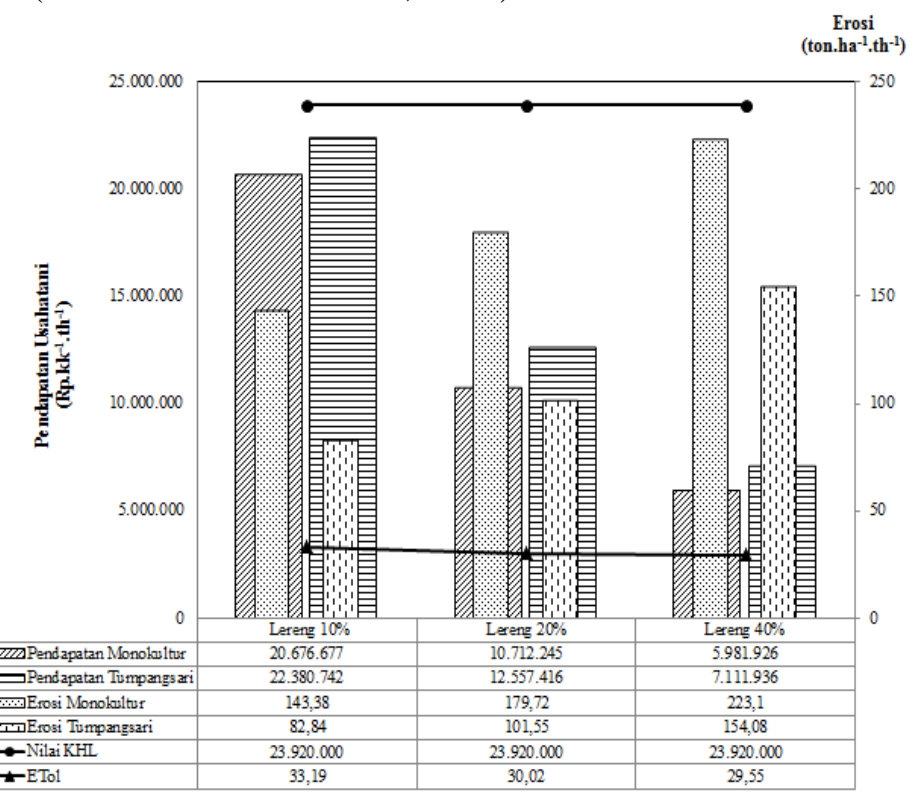

Gambar 2. Grafik hubungan antara erosi, ETol, pendapatan usahatani, dan KHL petani berdasarkan pola tanam dan kemiringan lereng. 
Berdasarkan nilai faktor CP tersebut, maka dibuat suatu percobaan lapangan teknologi KTA yang lebih difokuskan pada penerapan guludan dengan penyempurnaan dari beberapa segi. Pada kenyataan di lapangan, budidaya tanaman cabai merah dataran tinggi dilakukan dalam guludanguludan searah lereng. Oleh sebab itu perlu dicari ukuran dan bentuk guludan yang sesuai dengan agroekosistem dataran tinggi tanpa mengabaikan kebiasaan petani, namun dapat mengendalikan aliran permukaan dan erosi sampai batas yang ditoleransi, meningkatkan produksi tanaman dan pendapatan usahatani, serta dapat diterima (acceptable) dan dapat dikembangkan (replicable) oleh petani setempat.

\section{Pengaruh Teknik KTA Terhadap Aliran Permukaan, Erosi, Kehilangan Unsur Hara, Produksi Tanaman dan Pendapatan Usahatani}

Hasil analisis ragam menunjukkan bahwa perlakuan teknik KTA pada usahatani cabai merah monokultur dan tumpangsari berpengaruh nyata terhadap aliran permukaan, erosi tanah, kehilangan unsur hara, produksi tanaman dan pendapatan usahatani. Rata-rata aliran permukaan, erosi tanah, kehilangan unsur hara, produksi tanaman dan pendapatan usahatani dengan hasil uji BNT (P < 0,05) disajikan pada Tabel 4.

Berdasarkan hasil uji BNT, perlakuan $\mathrm{T}_{2} \mathrm{~K}_{3}$ nyata paling efektif menurunkan aliran permukaan dan erosi di bawah nilai ETol (30,92 ton.ha ${ }^{-1} \cdot$ th $\left.^{-1}\right)$, disusul kemudian perlakuan $\mathrm{T}_{1} \mathrm{~K}_{3}, \mathrm{~T}_{2} \mathrm{~K}_{4}, \mathrm{~T}_{1} \mathrm{~K}_{4}, \mathrm{~T}_{2} \mathrm{~K}_{2}$ dan $T_{1} K_{2}$. Guludan memotong lereng sangat efektif dalam memperlambat aliran permukaan dan menahan serta menampungnya agar lebih banyak air yang meresap ke dalam tanah melalui proses infiltrasi sehingga aliran permukaan dan erosi menjadi kecil (Zhang dkk., 2004; Shukle dan Lal, 2005; Asmaranto dan Juwono, 2007; Mawardi, 2013).

Sistem penanaman tumpangsari juga sangat baik untuk konservasi tanah karena penutupan tajuk lebih luas daripada monokultur. Semakin luas penutupan tajuk dan semakin rapat pertanaman,

Tabel 4. Pengaruh tindakan konservasi terhadap aliran permukaan, erosi, kehilangan unsur hara, produksi tanaman dan pendapatan usahatani.

\begin{tabular}{|c|c|c|c|c|c|c|c|c|c|}
\hline \multirow[t]{2}{*}{$\begin{array}{l}\text { Perla- } \\
\text { kuan }\end{array}$} & \multirow{2}{*}{$\begin{array}{c}\text { Aliran } \\
\text { permukaan } \\
\left(\mathrm{m}^{3}\right)\end{array}$} & \multirow[t]{2}{*}{$\begin{array}{c}\text { Erosi } \\
\left(\text { ton.ha }^{-1} \cdot \mathrm{th}^{-1}\right)\end{array}$} & \multicolumn{4}{|c|}{$\begin{array}{l}\text { Kehilangan unsur hara } \\
\left(\mathrm{kg} \cdot \mathrm{ha}^{-1} \cdot \mathrm{th}^{-1}\right)\end{array}$} & \multicolumn{2}{|c|}{$\begin{array}{c}\text { Produksi } \\
\left(\mathrm{kg} \cdot \mathrm{ha}^{-1} \cdot \mathrm{th}^{-1}\right)\end{array}$} & \multirow[t]{2}{*}{$\begin{array}{l}\text { Pendapatan } \\
\left(\text { Rp.ha }{ }^{-1} \cdot \mathrm{th}^{-1}\right)\end{array}$} \\
\hline & & & C-Org & NTotal & $\mathrm{P}_{2} \mathrm{O}_{5}$ & $\mathrm{~K}_{2} \mathrm{O}$ & Cabai & Kubis & \\
\hline $\mathrm{T}_{1} \mathrm{~K}_{1}$ & $253,35^{\mathrm{a}}$ & $109,08^{\mathrm{a}}$ & $2.677^{\mathrm{a}}$ & $342,5^{\mathrm{a}}$ & $31,3^{\mathrm{a}}$ & $54,1^{\mathrm{a}}$ & $3.951^{\mathrm{a}}$ & - & $41.449 .813^{\mathrm{a}}$ \\
\hline $\mathrm{T}_{1} \mathrm{~K}_{2}$ & $195,89^{b}$ & $28,74^{\mathrm{b}}$ & $1.974^{\mathrm{b}}$ & $253,8^{b}$ & $14,9^{\mathrm{b}}$ & $25,6^{\mathrm{b}}$ & $7.901^{\mathrm{b}}$ & - & $104.288 .479^{b}$ \\
\hline $\mathrm{T}_{1} \mathrm{~K}_{3}$ & $92,74^{\mathrm{d}}$ & $10,66^{\mathrm{d}}$ & $1.083^{\mathrm{d}}$ & $80,3^{\mathrm{d}}$ & $7,7^{\mathrm{d}}$ & $14,5^{\mathrm{d}}$ & $10.535^{\mathrm{d}}$ & - & $143.727 .013^{\mathrm{d}}$ \\
\hline $\mathrm{T}_{1} \mathrm{~K}_{4}$ & $130,76^{c}$ & $18,43^{\mathrm{c}}$ & $1.622^{c}$ & $156,5^{c}$ & $12,0^{c}$ & $16,6^{c}$ & $9.083^{c}$ & - & $121.175 .813^{c}$ \\
\hline $\mathrm{T}_{2} \mathrm{~K}_{1}$ & $203,57^{\mathrm{a}}$ & 89 & $969^{\mathrm{a}}$ & $229,8^{a}$ & $14,9^{\mathrm{a}}$ & $34,4^{\mathrm{a}}$ & $3.826^{\mathrm{a}}$ & $2.144^{\mathrm{a}}$ & $42.353 .359^{\mathrm{a}}$ \\
\hline $\mathrm{T}_{2} \mathrm{~K}_{2}$ & $143,56^{\mathrm{b}}$ & $19,29^{b}$ & $464^{b}$ & $175,5^{b}$ & $7,7^{b}$ & $18,4^{\mathrm{b}}$ & $7.897^{\mathrm{b}}$ & $5.387^{b}$ & $110.965 .958^{b}$ \\
\hline $\mathrm{T}_{2} \mathrm{~K}_{3}$ & $60,21^{\mathrm{d}}$ & $5,22^{d}$ & $224^{\mathrm{d}}$ & $44,1^{\mathrm{d}}$ & $3,5^{\mathrm{d}}$ & $9,3^{d}$ & $10.106^{\mathrm{d}}$ & $7.740^{\mathrm{d}}$ & $147.892 .612^{\mathrm{d}}$ \\
\hline $\mathrm{T}_{2} \mathrm{~K}_{4}$ & $95,11^{\mathrm{c}}$ & $11,46^{c}$ & $360^{c}$ & $125,4^{\mathrm{C}}$ & $5,67^{c}$ & $17,1^{\mathrm{c}}$ & $8.957^{c}$ & $6.042^{c}$ & $127.335 .944^{c}$ \\
\hline
\end{tabular}

Sumber : Data primer (2014).

* Angka-angka yang diikuti oleh huruf yang sama pada kolom yang sama tidak berbeda nyata pada taraf $5 \%$ menurut BNT

Erosi
$($ ton
$h^{-1} \cdot$ th $\left.^{-1}\right)$

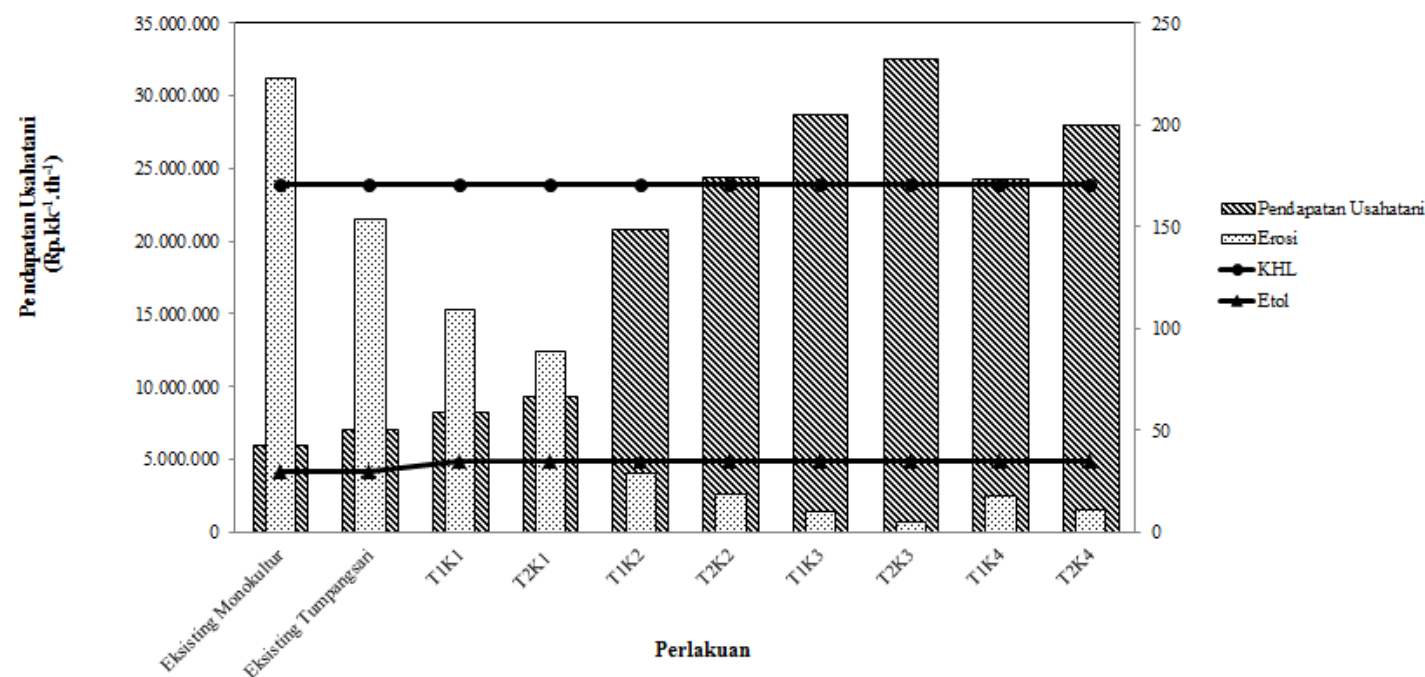

Gambar 3. Grafik hubungan antara erosi, ETol, pendapatan usahatani dan KHL petani pada berbagai teknik KTA. 
jumlah air yang lolos menembus tajuk dan sampai ke permukaan semakin kecil sehingga erosi yang terjadi juga semakin kecil. Peranan penutupan tajuk dalam menurunkan persentase hujan yang mengalir sebagai aliran permukaan, selain karena adanya reduksi energi kinetik hujan juga karena lebih banyak curah hujan yang diintersepsi oleh tajuk tanaman (Auerswald dkk., 2006; Sumarni dkk., 2006; Zhou dkk., 2008).

Berdasarkan Tabel 4, perlakuan $\mathrm{T}_{2} \mathrm{~K}_{3}$ nyata paling efektif menurunkan jumlah C-organik dan hara N,P,K yang hilang terbawa erosi, disusul kemudian perlakuan $\mathrm{T}_{1} \mathrm{~K}_{3}, \mathrm{~T}_{2} \mathrm{~K}_{4}, \mathrm{~T}_{1} \mathrm{~K}_{4}, \mathrm{~T}_{2} \mathrm{~K}_{2}$ dan $\mathrm{T}_{1} \mathrm{~K}_{2}$. Hal ini disebabkan oleh jumlah C-organik dan hara N, P dan K yang hilang tergantung dari jumlah aliran permukaan dan tanah yang tererosi, dimana jumlah aliran permukaan dan erosi perlakuan $\mathrm{T}_{2} \mathrm{~K}_{3}$ nyata lebih kecil, disusul kemudian perlakuan $\mathrm{T}_{1} \mathrm{~K}_{3}$, $T_{2} K_{4}, T_{1} K_{4}, T_{2} K_{2}$ dan $T_{1} K_{2}$. Apabila erosi berjalan terus-menerus pada permukaan tanah, maka dengan sendirinya akan terangkut partikel liat dan humus serta partikel tanah lainnya yang kaya akan unsur hara. Oleh karena itu jumlah unsur hara yang hilang oleh erosi tergantung pada besarnya erosi dan unsur hara yang terkandung dalam tanah yang tererosi (Utami, 2001; Chen dkk., 2013; El Kateb dkk., 2013).

Tabel 4 menunjukkan bahwa perlakuan teknik KTA baik pada pola tanam monokultur maupun tumpangsari berpengaruh nyata terhadap produksi tanaman dan pendapatan usahatani. Hasil produksi cabai merah tumpangsari (perlakuan $\mathrm{T}_{2} \mathrm{~K} 1, \mathrm{~T}_{2} \mathrm{~K}_{2}$, $\mathrm{T}_{2} \mathrm{~K}_{3}$, dan $\mathrm{T}_{2} \mathrm{~K}_{4}$ ) lebih rendah daripada hasil produksi cabai merah monokultur (perlakuan $\mathrm{T}_{2} \mathrm{~K}_{1}, \mathrm{~T}_{2} \mathrm{~K}_{2}$, $\mathrm{T}_{2} \mathrm{~K}_{3}$, dan $\mathrm{T}_{1} \mathrm{~K}_{4}$ ). Hal ini diduga disebabkan oleh adanya persaingan penyerapan unsur hara antara tanaman utama dengan tanaman tumpangsarinya, sehingga pertumbuhan tanaman cabai merah tumpangsari tidak maksimal dan produksinya lebih rendah dibandingkan dengan tanaman cabai merah monokultur.

Meskipun produksi tanaman cabai merah pada perlakuan tumpangsari lebih rendah, namun sumbangan produksi tanaman tumpangsarinya (kubis) mampu memberikan pendapatan usahatani yang tinggi. Pendapatan usahatani nyata paling tinggi pada perlakuan $\mathrm{T}_{2} \mathrm{~K}_{3}$, yaitu sebesar $\mathrm{Rp}$. 147.892.612 ha ${ }^{-1} \cdot$ th $^{-1}$. Menurut Suwandi (2009) serta Soetiarso dan Setiawati (2010) selain produksi kumulatif lebih tinggi, tumpangsari juga dapat memberikan keuntungan lain, yaitu dapat meningkatkan Nilai Kesetaraan Lahan (NKL) lebih dari satu dan keuntungan ekonomi.

Berdasarkan berbagai alternatif perlakuan teknik KTA diperoleh nilai erosi dan pendapatan usahatani berdasarkan rata-rata luas garapan petani seperti yang disajikan pada Gambar 3. Gambar tersebut menunjukkan bahwa perlakuan $\mathrm{T}_{1} \mathrm{~K}_{3}, \mathrm{~T}_{1} \mathrm{~K}_{4}$ , $\mathrm{T}_{2} \mathrm{~K}_{3}$ dan $\mathrm{T}_{2} \mathrm{~K}_{4}$ dapat diterapkan pada lahan dataran tinggi karena mampu menurunkan erosi $\leq$ nilai ETol (30,92 ton.ha $\left.{ }^{-1} \cdot \mathrm{th}^{-1}\right)$ dan meningkatkan pendapatan usahatani $\geq$ nilai KHL (Rp. 23.920.000 $\mathrm{kk}^{-1} \cdot \mathrm{th}^{-1}$ ).

Besar erosi perlakuan $\mathrm{T}_{1} \mathrm{~K}_{3}, \mathrm{~T}_{1} \mathrm{~K}_{4}, \mathrm{~T}_{2} \mathrm{~K}_{3}$ dan $\mathrm{T}_{2} \mathrm{~K}_{4}$ berturut-turut adalah 10,66, 18,43, 5,22 dan 11,46 ton.ha ${ }^{-1} \cdot \mathrm{th}^{-1}$, sedangkan pendapatan usahatani perlakuan $\mathrm{T}_{1} \mathrm{~K}_{3}, \mathrm{~T}_{1} \mathrm{~K}_{4}, \mathrm{~T}_{2} \mathrm{~K}_{3}$ dan $\mathrm{T}_{2} \mathrm{~K}_{4}$ berturut-turut adalah sebesar Rp. 28.745.403, Rp. 24.235.163, Rp. 32.536.375 dan Rp. 28.013.908 $\mathrm{kk}^{-1} . \mathrm{th}^{-1}$. Dengan demikian keberlanjutan lingkungan dan ekonomi dapat tercapai melalui penyempurnaan teknik pengelolaan usahatani berupa teknik KTA yang sesuai

\section{KESIMPULAN}

Erosi yang terjadi di lahan usahatani tanaman cabai lebih besar dari batas ETol dan termasuk dalam kategori sangat tinggi. Erosi yang sangat tinggi ini disebabkan oleh intensitas hujan yang tinggi, kemiringan lereng yang curam dan efektivitas penutupan tanah dan pengelolaan tanaman yang rendah.

Pendapatan usahatani cabai merah di dataran tinggi Kecamatan Cikajang lebih rendah dari KHL petani. Kontribusi pendapatan usahatani cabai merah terhadap pemenuhan KHL petani semakin rendah seiring dengan kemiringan lereng yang semakin curam. Berdasarkan pada pola tanam, kontribusi pendapatan usahatani pada pola tanam tumpangsari lebih tinggi daripada kontribusi pola tanam monokultur.

Perlakuan $\mathrm{T}_{1} \mathrm{~K}_{3}, \mathrm{~T}_{1} \mathrm{~K}_{4}, \mathrm{~T}_{2} \mathrm{~K}_{3}$ dan $\mathrm{T}_{2} \mathrm{~K}_{4}$ efektif menurunkan aliran permukaan dan menekan erosi di bawah batas ETol, menurunkan jumlah C-organik dan unsur hara yang terbawa erosi sehingga dapat meningkatkan produktivitas tanaman dan meningkatkan pendapatan usahatani di atas nilai KHL petani. Keberlanjutan lingkungan dan ekonomi dapat tercapai melalui penyempurnaan teknik KTA yang sesuai.

\section{DAFTAR PUSTAKA}

Adiyoga, W., Ameriana, M., Suherman, R., Soetiarso, T.A., Udhiarto, B.K., dan Sulastrini, I., 2000. Sistem Produksi Beberapa Jenis Sayuran di Indonesia. J. Hort. 9(2):258-265.

Agus, F., Irawan, Nurida, N.L., Dariah, A., dan Husen, E., 2006. Konversi Lahan Pertanian Sebagai Suatu Ancaman Terhadap Ketahanan Pangan dan Kualitas Lingkungan. Prosiding Seminar Multifungsi dan Revitalisasi 
Pertanian. Badan Penelitian dan Pengembangan Pertanian. Bogor. pp. 101-121. Anonim, 2005. Rencana Aksi Pemantapan Ketahanan Pangan 2005-2010. Badan Penelitian dan Pengembangan Pertanian. Departemen Pertanian. Jakarta.

Anonim, 2013. Profil Kawasan Cabai Merah di Kabupaten Garut. Dinas Tanaman Pangan dan Hortikultura. Garut.

Anonim, 2014. Statistik Indonesia 2013. Badan Pusat Statistik. Jakarta.

Armand, R., Bockstaller, C., Auzet, A.V., dan Van Dijk, P., 2009. Runoff Generation Related to Intra Field Soil Surface Characteristics Variability: Application to Conservation Tillage Context. Soil Tillage Res. 102:27-37.

Arsanti, I.W., dan Boehme, M., 2006. Sistem Usahatani Tanaman Sayuran di Indonesia: Apresiasi Multifungsi Pertanian, Ekonomi dan Eksternalitas Lingkungan. Seminar Multifungsi Pertanian. Badan Penelitian dan Pengembangan Pertanian. Departemen Pertanian. Lido, 26 - 27 Juni 2006.

Arsyad, S., 2010. Konservasi Tanah dan Air. Edisi Kedua. IPB Press. Bogor.

Asdak, C., 2007. Hidrologi dan Pengelolaan Daerah Aliran Sungai. Gadjah Mada University Press. Yogyakarta.

Asmaranto, R., dan Juwono, 2007. Analisis Laju Erosi dan Arahan Konservasi di DAS Pikatan Mojokerto Berbasis Sistem Informasi Geografis. J. Teknik, 14(1):5-17.

Auerswald, K., Gerl, G., dan Kainz, M., 2006. Influence of Cropping System on Harvest Erosion under Potato. Soil and Tillage Research, 89:22-34.

Berke, T.G., Black, L.L., Green, S.K., Morris, R.A., Talaker, N.S., dan Wang, J.F., 2005. Suggested Cultural Practices For Sweet Pepper. Asian Vegetable Research and Development Center (AVRDC) Publication, 9:9-49.

Chen, L., Liu, D.F., Song, L.X., Cui, Y.J., dan Zhang, G., 2013. Characteristis of Nutrient Loss by Runoff in Sloping Arable Land of Yellow-Brown under Different Rainfall Intensities. J. Environmental Science 34(6):2151-2158.

Dariah, A., 2007. Budidaya Pertanian pada Lahan Pegunungan. Warta Penelitian dan Pengembangan Pertanian Indonesia, 29(1):710.

Daryanto, A., Sriani, S., dan Muhamad, S., 2010. Heterosis dan Daya Gabung Karakter Agronomi Cabai (Capsicum annuum L.) Hasil Persilangan Half Diallel. J. Agron. Indonesia, 38(2):113-121.
El Kateb, H., Zhang, H., Zhang, P., dan Mosandl, R., 2013. Soil Erosion and Surface Runoff on Different Vegetation Covers and Slope Gradients: A Field Experiment in Southern Shaanxi China. J. Catena 105(6):1-10.

Firmansyah, 2007. Prediksi Erosi Tanah Podsolik Merah Kuning Berdasarkan Metode USLE di Berbagai Sistem Usahatani: Studi Kasus di Kabupaten Barito Utara dan Gunung Mas. J. Pengkajian dan Pengembang Teknologi Pertanian, 10:2-29.

Gangcai, L., Zhang, J., Tian, G., dan Wei, C., 2005. The Effects of Land Uses on Purplish Soil Erosion in Hilly Area of Sichuan Province, China. Journal of Mountain Science, 2(1):6875.

Goro, G.L., 2008. Kajian Pengaruh Intensitas Hujan pada Jenis Tanah Regosol Kelabu untuk Kemiringan Lereng yang Berbeda. Wahana Teknik Sipil, 13(2):86-98.

Gunaeni, N., dan Wulandari, A.W., 2010. Cara Pengendalian Non Kimiawi Terhadap Serangga Vektor Kutu Daun dan Intensitas Serangan Penyakit Virus Mosaik pada Tanaman Cabai Merah. J. Hort., 20(4):68-76.

Hardiyatmo, H.C., 2006. Penanganan Tanah Longsor dan Erosi. Gadjah Mada University Press. Yogyakarta.

Hogarth, W.L., Parlange, J.Y., Rose, C.W., Sander, G.C., Stenhuis, T.S., dan Barry, A., 2004. Soil Erosion Due to Rainfall Impact with Inflow : An Analytical Solution with Spatial and Temporal Effect. J. Hidrology, 295(14):140148.

Lihawa, F.,Partuti, I.M., dan Nurfaika, 2014. Sebaran Aspek Keruangan Tipe Longsoran di Daerah Aliran Sungai Alo Provinsi Gorontalo. J. Manusia dan Lingkungan, 21(3):277-285.

Li, Y.X., Tullberg, J.N., Freebairn, D.M., dan Li, H.W., 2009. Functional Relationship between Soil Water Infiltration and Wheeling Rainfall Energy. Soil Tillage Res., 104:156-163.

Mawardi, 2013. Analisis Faktor Konservasi Kombinasi Teras Nikolas dan Tanaman Kacang Tanah (Faktor CP untuk Teras Nikolas + Kacang Tanah). Wahana Teknik Sipil, 18(2):30-40.

Pasandaran, E., 2006. Alternatif Kebijakan Pengendalian Konversi Lahan Sawah Beririgasi di Indonesia. J. Penelitian dan Pengembangan Pertanian, 25(4):123-129.

Prasetyo, B.H., dan Suriadikarta, D.A., 2006. Karakteristik, Potensi, dan Teknologi Pengolahan Tanah Ultisol untuk Pengembangan Pertanian Lahan Kering di 
Indonesia. J. Penelitian dan Pengembangan Pertanian, 25(2):39-46.

Respati, E., Hasanah, L., Wahyuningsih, S., Sehusman, Manurung, M., Supriyati, Y., dan Rinawati, 2014. Konsumsi Pangan Indonesia. Buletin Konsumsi Pangan, 4(3):17-22.

Sevila, C.G., Ochave, J.A., Punsalam, T.G., Regala, B.P., dan Uriarte, G.G., 1993. Pengantar Metode Penelitian. Universitas Indonesia Press. Jakarta.

Shukle, M.K., dan Lal, R., 2005. Erosional Effect on Soil Physical Properties in an on-Farm Study on Alfisols in West Central Ohio. J. Soil Sci. Am., 170(6): 445-456.

Sinukaban, N., 2007. Membangun Pertanian Menjadi Industri yang Lestari dengan Pertanian Konservasi. Dalam: Sinukaban N., Konservasi Tanah dan Air Kunci Pembangunan Berkelanjutan. Direktorat Jenderal RLPS. Departemen Kehutanan. Jakarta. pp. 226-241.

Soekartawi, 2006. Analisis Usahatani. Universitas Indonesia Press. Jakarta.

Soetiarso, T.A., dan Setiawati, W., 2010. Kajian Teknis dan Ekonomis Sistem Tanam Dua Varietas Cabai Merah di Dataran Tinggi. J. Hort., 20(3): 84-98.

Sumarni, N., Hidayat, A., dan Sumiati, E., 2006. Pengaruh Tanaman Penutup Tanah dan Mulsa
Organik terhadap Produksi Cabai dan Erosi Tanah. J. Hort., 16(3):197-201.

Sutono, S., 2008. Kerugian Petani Akibat Erosi. Warta Sumberdaya Lahan 3(4):1-5.

Sutrisna, N., Sitorus, S.R.P., Pramudya, B., dan Harianto, 2010. Alternatif Model Usahatani Konservasi Tanaman Sayuran di Hulu Sub DAS Cikapundung. J. Hort., 20(3):223-240.

Suwandi, 2009. Menakar Kebutuhan Hara Tanaman dalam Pengembangan Inovasi Budidaya Sayuran Berkelanjutan. J. Pengembangan Inovasi Pertanian 2(2):131-147.

Utami, U.B.L., 2001. Pengaruh Tindakan Konservasi Tanah Terhadap Aliran Permukaan, Erosi, Kehilangan Hara dan Penghasilan pada Usahatani Kentang dan Kubis. J. Manusia dan Lingkungan, 3(2):98-107.

Zhang, J., Frielinghaus, M., Tian, G., dan Lobb, D.A., 2004. Ridges and Contour Tillage Effect on Soil Erosion from Hillslope in The Sichuan Basin China. J. Soil and Water Conservation, 90:123-134.

Zhou, P., Luukkanen, O., Tokola, T., dan Nieminen, J., 2008. Effect of Vegetation Cover on Soil Erosion in a Mountainous Watershed. $J$. Catena, 75(4): 319-325. 